4.

\title{
Verkalkte Gehiruzellen.
}

\author{
Von Dr. Wiedemeister, \\ zweitem trat der provinzialständischen Irrenanstalt zu 0snabrủck.
}

(Briefliche Mittheilung an den Herausgeber.)

In Folge Ihrer im letzten Hefte Ilsres Archivs (Bd. L. S. 304) enthaltenen Bemerkungen über Verkalkung abgestorbener Gehirnzellen darf ich mir erlauben lhnen die Mittheilung zu machen, dass ich ein Prăparat verkalkter Gehirnganglienzellen besitze.

Dasselbe stammt von einer im Jahre 1861 verstorbenen Jüdin:

Louise Meyer, 53 Jahre alt, einern liederlichen Lebenswandel und bis in die jüngste Zeit vor ihrer Erkrankung geschlechtlichen Genüssen ergeben, um Weihnacht 1860 geistig erkrankt, ward am 27. April 1861 in die Heil-Anstalt zu Hildesheim aufgenommen, wo sie am 25. Juli desselben Jabres in einem frühen Stadium der progressiven Haralyse verstarb. Am 15. Juni bekam sie einen apoplectischen Anfall mit Lähmung der rechten Körper- und linken Gesichtsbälfte, welche schon am nüchsten Tage fast vollständig wieder geschwunden war, und auf eine Verstopfung der linken Art. fossae Sylvii bezogen wurde. Vier Wochen später entstand ein Carbunkel und am 25. Juli starb sie. Bei der Section fand sich in dem erwăhnten Gefässe ein derber faserstoffiger Embolus, der sich in den vorderen Ast der Arterie von der Theilungsstelle aus erstreckte, der Arterienwand anhing, aber das Lumen nicht vollständig verschloss. - Im Verbreitungsbezirk dieses Astes nahe der Spitze der Hemisphäre an der unteren Fläche zeigte sich ein nekrotischer Erweichungsheerd von der Grösse einer Krachmandel, gefüllt mit einer gallertartigen Masse in einem siebförmig durchlöcherten Gewehe. Hierin wurden bei der mikroskopisclen Untersuchung die verkalkten Ganglienzelien, eine grosse Menge von Corpp. amylacea und colloidea, von denen eistere deutliche Jodreaction zeigten, Fettkörnchenzellen, zertrümmerte Nervenröhren, sowie ein kleines knochenartiges Plättchen gefunden. Die Valvula mitralis cordis etwas geschrumpft, ihre freien Ränder mit einzelnen Vegetationen von Mohnsamengrösse bis darüber besetzt.

Die Ganglienzellen unterscheiden sich ron den von Förster abgebildeten Ganglienzellen des Rückenmarks, abgesehen von ihrer schlankeren und durch geradere Linien schärfer begrenzten dreiseitigen Gestalt, dadurch, dass auch der verkalkte Kern deutlich sichtbar ist. Die Fortsätze sind natürlich abgerissen.

D r u c k f h le r.

Seite 359 Zeile 11 v. u. lies: $0,03-0,21$ statt: $0,03-0,125$

- $360-10$ v. o. lies: des Ansteigens von der ursprünglichen Temperatur an $16-34$ Minuten statt: des Ansteigens $6-26$ Minuten 